\title{
Spermatogenesis of the green-lipped mussel Perna viridis with dual patterns of acrosome and tail development in spermatids
}

Received: 22 July 1998 / Accepted: 12 September 1998

\begin{abstract}
Spermatogenesis in the mussel Perna viridis was studied by electron microscopy. Results demonstrated that cytological development in spermatogonia and spermatocytes was similar to that previously described in other Mytilidae. Acrosome formation began with the arising of proacrosomal vesicles in spermatogonia. The abundance of proacrosomal vesicles increased in spermatocytes, which were flagellated. However, during spermiogenesis, dual patterns of acrosome development as well as flagellum development could be found among spermatids in a male gonad. The two lines of acrosome formation in spermatids ultimately gave rise to morphologically similar acrosomes. The two lines of flagellum development in spermatids resulted in the formation of sperm cells with either a typically posteriorly directed tail or an anteriorly directed tail.
\end{abstract}

Key words Spermatogenesis $\cdot$ Perna viridis . Acrosome formation - Flagellum development

\section{Introduction}

Spermatogenesis and sperm structure have been reported for the Mytilidae (Longo and Dornfeld 1967; Hodgson and Bernard 1986 a,b; Reunov and Drozdov 1987; Reunov and Hodgson 1994). The results of previous studies showed that the Mytilidae possess "primitive" spermatozoa (Franzen 1956) which are typically found in invertebrates with external fertilization. In some mytilids such as Mytilus edulis, M. galloprovincialis (Hodgson and Bernard 1986 a,b), M. coruscus (Reunov and Drozdov 1987), Perna perna (Bernard and Hodgson 1985), and

\section{A.A. Reunov}

Institute of Marine Biology, Far East Branch of Russian Academy of Sciences, 17 Paltchevsky Street, 690041 Vladivostok, Russia

D.W.T. Au ( $)$ R.S.S. Wu

Department of Biology and Chemistry, City University of Hong Kong, 83 Tat Chee Avenue, Kowloon, Hong Kong e-mail: bhdwtau@ cityu.edu.hk

Fax: (852) 27887406
Brachidontes semistriatus (Reunov and Hodgson 1994), the spermatozoa possess an elongated acrosome with an internal actin axial rod, and the axial rod projects anteriorly to the egg chorion during the acrosomal reaction (Niijima and Dan 1965; Tilney et al. 1987). In other mytilids, such as Adula falcatoides, Modiolus kurillensis, Septifer keenae (Drozdov and Reunov 1986; Reunov and Drozdov 1986), Aulacomya ater, Choromytilus meridionalis (Hodgson and Bernard 1986 b), and Arcuatula capensis (Reunov and Hodgson 1994), the spermatozoa possess a cup-form acrosome without an actin axial rod, and only a short filament projects during the acrosomal reaction (Reunov and Drozdov 1992).

Spermatogenesis among the various mytilid species studied was basically similar (Reunov and Drozdov 1987; Reunov and Hodgson 1994). In Mytilidae, as well as in Arcidae and Veneridae, pre-spermiogenic cells (spermatogonia and spermatocytes) possess a single flagellum; and acrosome formation begins with the formation of proacrosomal vesicles from Golgi bodies in spermatogonia and spermatocytes. In early spermatids, the proacrosomal vesicles aggregate to form a single acrosomal vesicle near the presumptive posterior of the cell. In late spermatids, the acrosomal vesicle migrates to the presumptive anterior of the spermatozoon where it undergoes further maturation.

Only a single pattern of cell differentiation has been reported in spermatogenesis of mytilids. In our preliminary TEM study, we have revealed some unusual cytological features during acrosome and tail development in spermatids of the mytilid Perna viridis L. The greenlipped mussel, $P$. viridis, is a dominant species in the intertidal zone in the Indo-Pacific and Caribbean (Agard et al. 1992). This species appears to occupy a similar ecological niche and habitat as Mytilus edulis in the temperate region. The population structure and dynamics of $P$. viridis (Huang et al. 1985; Cheung 1993a), its physiological ecology (Cheung 1993b), growth and reproduction (Lee 1986; Cheung 1991) have been well studied. Spermatogenesis of $P$. viridis, however, remains poorly known. The aim of this paper is to document the ultra- 
Fig. 1 Transmission electron micrographs (TEM) of early spermatogenic cells. A Spermatogonium $(S g)$, and spermatocyte $(S c)$ with a synaptonemal complex (arrowhead) inside the nucleus $(N)$. B Spermatogonium with a pair of centrioles (arrowheads). C Spermatocyte with a flagellum $(F)$ originated from the distal centriole $(D C) . M$, Mitochondrion; $\mathrm{Nu}$ nucleolus; $P A V$ proacrosomal vesicles; $P C$ proximal centriole. Scale bars $1 \mu \mathrm{m}$
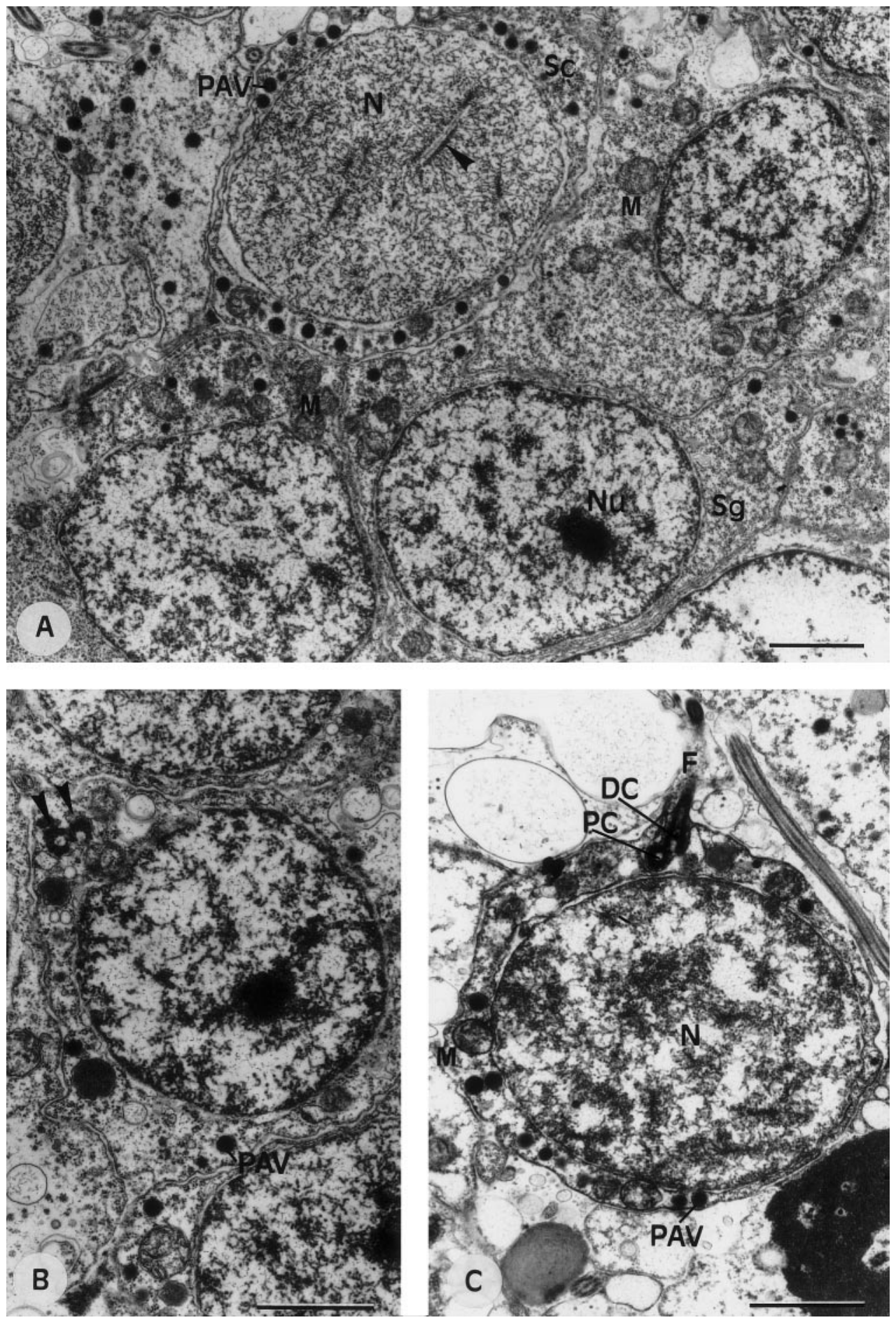

structural changes during spermatogenesis of $P$. viridis, with special attention to acrosome and tail development in spermatids.

\section{Materials and methods}

Green-lipped mussels, Perna viridis, were collected from the intertidal zone of Yim Tin Tsai, Hong Kong, during April-May 1997.

\section{Scanning electron microscopy}

Sperm suspension was prepared by crushing pieces of male gonad in filtered seawater. The suspension was centrifugated at $400 \mathrm{~g}$ for 4 min and sperms in the supernatant were pipetted onto a Thermanox coverslip (pre-coated with $0.1 \mathrm{mg}$ poly-L-lysine $/ \mathrm{kg}$ ) and allowed to settle for $1 \mathrm{~h}$. Coverslips with attached sperm cells were fixed in $2 \%$ glutaraldehyde in $0.1 \mathrm{M}$ cacodylate buffer for $2 \mathrm{~h}$ at room temperature, then rinsed several times in buffer and deionized water before being postfixed in $2 \%$ aqueous $\mathrm{OsO}_{4}$ in the dark for $1 \mathrm{~h}$. Samples were then dehydrated in ethanol solutions, acetone and critical-point dried in $\mathrm{CO}_{2}$. Dried materials were mounted 
Fig. 2 TEM of spermatids showing "typical" pattern of acrosomal development. A Individual proacrosomal vesicles (arrows) coalesce into an acrospermatid. B Despite insufficient fixation, a mass of electron-dense periacrosomal material (arrow) is clearly shown on the acrosomal vesicle $(A V)$ which is near the basal region acrosomal vesicle; the acrosomal cavity (arrow head) is filled up with periacrosomal material (asterisk); an electrondense region (arrow) lines the inner surface of the acrosomal membrane. D Spherical acrosomal vesicle $(A V)$ situated at the apical part of spermatid, elecrial is in contact with the nucleus $(N)$. E Acrosomal vesicle with a more invaginated base (arrow) and homogeneous texture. F Initial stage of acrosomal tip elongation (arrow). $\mathbf{G , H}$ Advanced stages of acrosomal tip elongation (arrowed). $D C$ Distal centriole; $M$ mitochondrion; $N$ nucleus; $P C$ proximal centriole; $T$ tail. Scale bars in $\mathbf{A}, \mathbf{C}, \mathbf{D}, \mathbf{F}-\mathbf{H}=0.5 \mu \mathrm{m}$; $\mathbf{B}, \mathbf{E}=1 \mu \mathrm{m}$ somal vesicle (star) in an early of the spermatid. C Invaginated tron-dense periacrosomal mate-
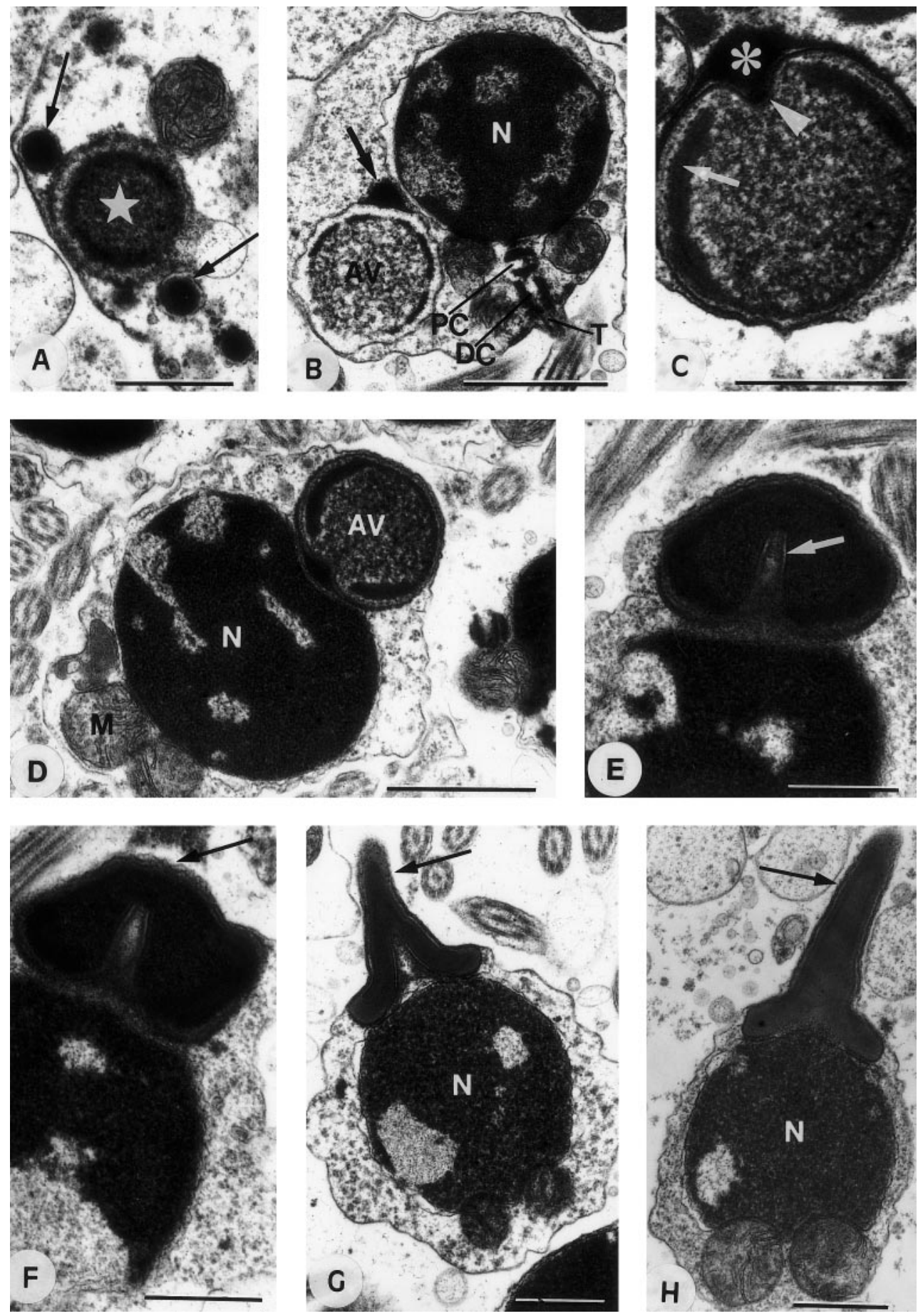

on to aluminum stubs, coated with gold, and examined with a Cambridge 360 scanning electron microscope at $20 \mathrm{kV}$.

Transmission electron microscopy

Gonads were removed from three male, cut into small pieces and fixed for $2-3 \mathrm{~h}$ (in $2.5 \%$ glutaraldehyde with $1 \%$ tannic acid in 0.1 $\mathrm{M}$ cacodylate buffer, $\mathrm{pH} 7.4$, with $0.25 \mathrm{M}$ sucrose) at room temperature. Primary fixed materials were washed gradually in the same buffer containing a decreased concentration of sucrose $(0.25$ $\mathrm{M}, 0.125 \mathrm{M}, 0.063 \mathrm{M})$, then to buffer only. Washed samples were postfixed in $2 \% \mathrm{OsO}_{4}$ in the dark for $2 \mathrm{~h}$, then rinsed in buffer and distilled water, dehydrated in a graded series of ethanol solutions, transferred to acetone, and infiltrated gradually in Spurr's resins before embedding. Ultrathin sections were stained in uranyl acetate and lead citrate and examined with a JEOL 100SX transmission electron microscope at $80 \mathrm{kV}$.

\section{Results}

\section{Spermatogenesis}

Spermatogonia of Perna viridis were ca. $3-5 \mu \mathrm{m}$ in diameter; the nucleus $(2-3 \mu \mathrm{m}$ in diam) was filled with 
Fig. 3 A-G TEM of spermatids showing the second pattern of acrosomal development. H, I TEM of spermatids with axonemes remaining inside cell. A Acrosomal vesicle $(A V)$ invaginated (arrowhead), situated at the basal region of spermatid. B Acrosomal vesicle $(A V)$ with an elongating tip ( $a r-$ row head), situated at the basal part of spermatid. C Acrosomal vesicle with an elongating tip (arrow head), situated on the apical region of nucleus. D Acrosomal vesicle with a bent tip (arrow head) and a wide base sitting on the apical region of the nucleus. $\mathbf{E}$ The bent acrosomal tip (arrowhead) delineates from the cytoplasm. F, G: Stages of acrosomal tip straightening (arrowheads). H: Middle spermatid with an axoneme (arrows) inside the cell. I Late spermatid with an axoneme (arrows) adjoining the sperm head. AR Axial rod; $M$ mitochondrion; $N$ nucleus; $T$ tail; Scale bars $=1 \mu \mathrm{m}$
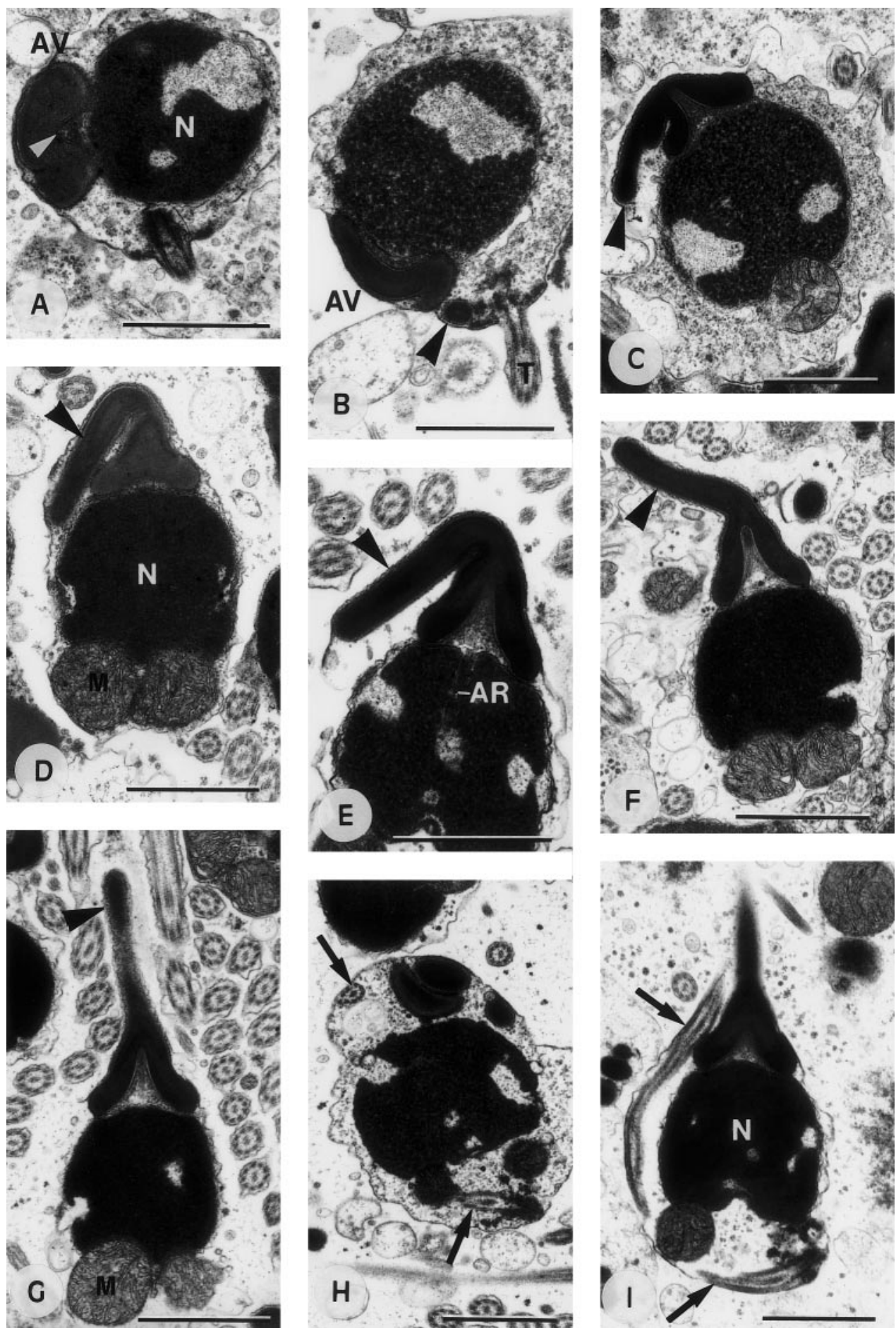

patches of electron-dense chromatin and had a prominent nucleolus. A few ovoid mitochondria and several discrete, electron-dense proacrosomal vesicles were scattered in the cytoplasm (Fig. 1A,B); a pair of centrioles was situated near the cell membrane (Fig. 1B).

The diameters of spermatocytes and nuclei were ca. 4-5 and 3-3.5 $\mu \mathrm{m}$, respectively. Spermatocytes I during zygotene meiotic prophase could be identified by the presence of synaptonemal complexes inside the nucleus (Fig. 1A). Compared to spermatogonia, spermatocytes contained more proacrosomal vesicles (Fig. 1A) and possessed a single flagellum originating from the distal centriole (Fig. 1C).

The early spermatid was ca. $3 \mu \mathrm{m}$ in diameter; the nucleus contained more condensed chromatin. Chromatin condensation accelerated during spermiogenesis and was almost completed in late spermatids. In early spermatids, mitochondria and proacrosomal vesicles concentrated near the centrioles. The small proacrosomal vesicles coalesced (Fig. 2A) and developed into a prominent acro- 
Fig. 4 A-E TEM of spermatozoa. A Median longitudinal section of sperm head. B Acrosomal cavity with periacrosomal material $(P M)$ and an axial actin $\operatorname{rod}(A R)$. $\mathbf{C}$ Higher magnification at the basal part of the spermatozoon shows a nuclear membrane partition ( $a r$ row) between the nuclear channel $(N C)$ and midpiece, an axial rod (white arrowhead) inside the nuclear channel; pericentriolar element (black arrowhead) associated with the proximal centriole. D Cross section at distal centriole shows the pericentriolar complex with radial oriented arms (arrowhead). E Cross section at midpiece shows a ring of five mitochondria (asterisk) surrounding an axoneme. F-G Scanning electron micrographs (SEM) of spermatozoa. F Spermatozoon with a typical posteriorly directed tail $(T)$. G Sperm cell with an anteriorly directed tail $(T)$ adjoining to the sperm head. $A$ acrosome; $A R$ axial rod; $D C$ distal centriole; $M$ mitochondrion; $N$ nucleus; $P C$ proximal centriole; $T$ tail. Scale bars in $\mathbf{A}, \mathbf{F}, \mathbf{G}=1 \mu \mathrm{m} ; \mathbf{B}, \mathbf{C}$, $\mathbf{D}=0.5 \mu \mathrm{m} ; \mathbf{E}=0.3 \mu \mathrm{m}$
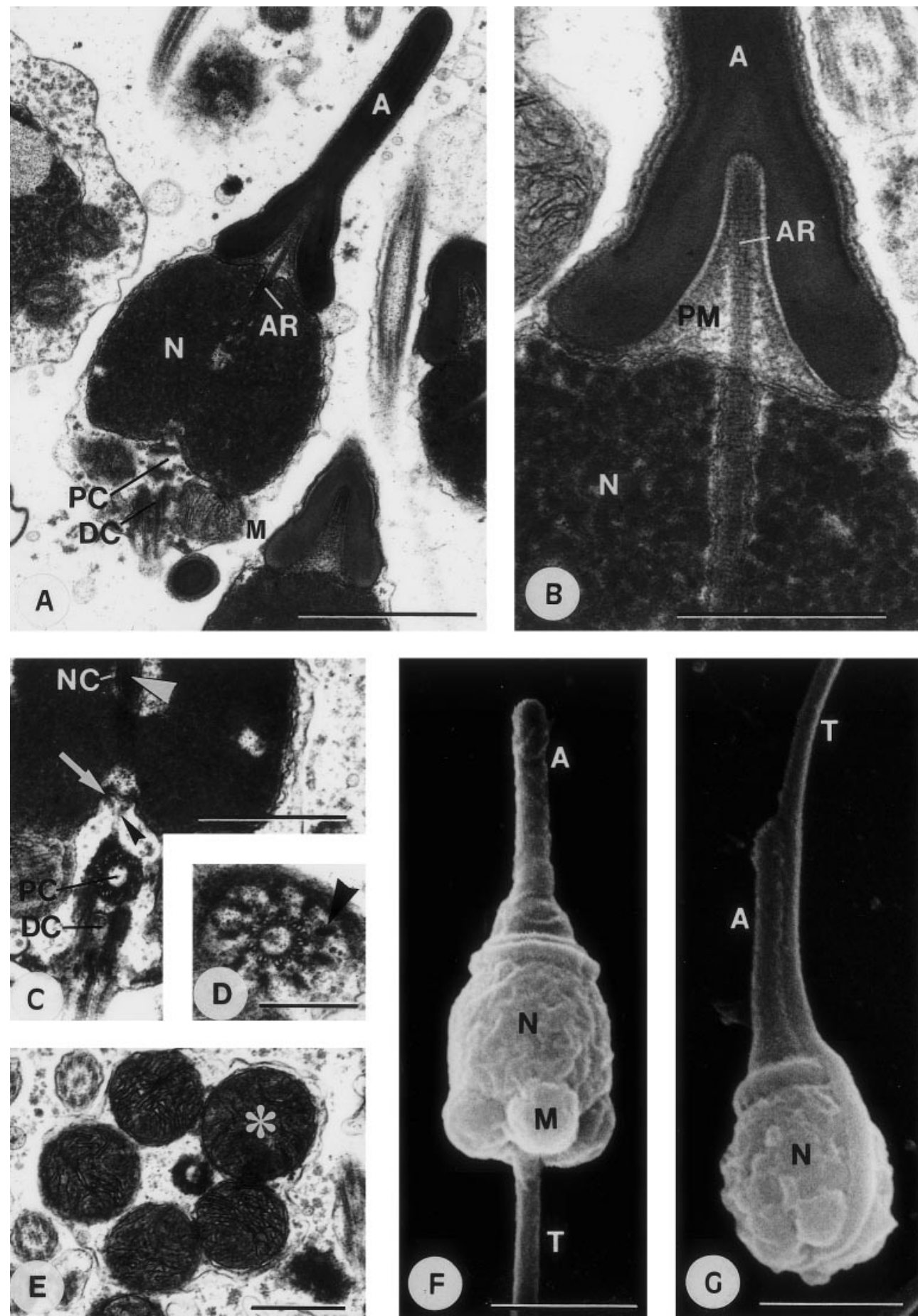

somal vesicle (ca. $0.8 \mu \mathrm{m}$ in diameter) (Fig. 2B). The acrosomal vesicle contained diffuse substances, with a discrete and electron-dense band along the inner membrane (Fig. 2C). A mass of electron-dense periacrosomal material located at the presumptive basal region of the acrosomal vesicle (Fig. 2B) where vesicle membrane invagination would take place (Fig. 2C).

During spermiogenesis, two lines of acrosomal vesicle development were evident. It is typical that the spherical acrosomal vesicle migrated to the presumptive anterior of the spermatid, with the basal invaginated region in contact with the anterior region of the nucleus (Fig. 2D). The acrosomal vesicle became more homogeneous in texture and continued to invaginate at the base (Fig. 2E). The acrosome tip elongated symmetrically apically, and the basal region widened slightly (Figs. $2 \mathrm{~F}-\mathrm{H})$. Nevertheless, in some cases we also observed invagination of the acrosomal vesicle (Fig. 3A) and elongation of the acrosomal tip (Fig. 3B) near the basal region of the spermatid prior to acrosomal migration. The 
Fig. 5 The seuence of spermiogenesis regarding acrosomal development. A-F the "typical" pattern. A'-F' the second pattern. G Spermatozoon. $a$ acrosome; $a v$ acrosomal vesicle; ar axial rod; $d c$ distal centriole; $m$ mitochondrion; $m p$ nuclear membrane partitition in centriolar fossa; $n$ nucleus; $p$ pericentriolar complex of distal centriole; $p c$ proximal centriole; $p e$ pericentriolar element of proximal centriole; $t$ tail

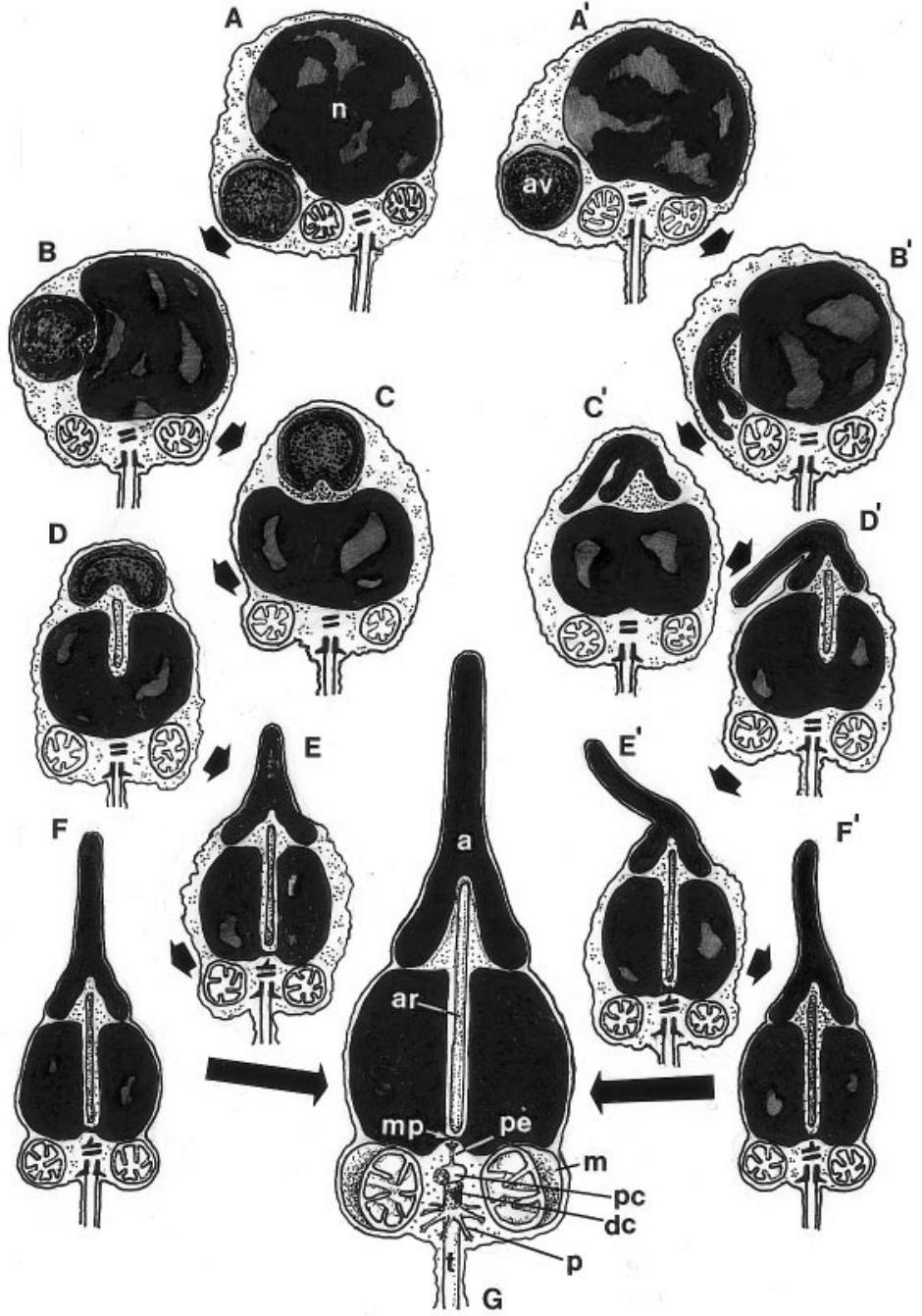

acrosomal tip continued to elongate upon reaching the anterior of the cell (Fig. 3C), remained inside the cytoplasm, and appeared to be "bent" in late spermatids (Fig. 3D). The bent acrosomal tip delineated from the cytoplasm (Fig. 3E) and eventually straightened (Fig. 3E-G).

Two patterns of tail development were also observed during spermiogenesis. Spermatids with a posteriorly oriented flagellum were typical (Figs. 2B; 3A,B). However, in some early spermatids, the axoneme coiled just under the plasma membrane (Fig. $3 \mathrm{H}$ ). The late spermatids developed from this line of spermiogenesis possessed an anteriorly directed tail which remained adjoining the spermatid head (Fig. 3I). Such an occurrence in spermatids was irrespective of the type of acrosomal development.

\section{Sperm structure}

The head length of the spermatozoan of $P$. viridis was 3.7 $\mu \mathrm{m}$ (Fig. 4A). The barrel-shaped nucleus $(1.3 \times 1.4 \mu \mathrm{m}$, height and width) was filled with electron-dense chromatin (Fig. 4A-C). The acrosome morphology was similar in result in spite of the two lines of its development during spermiogenesis. The funnel-shaped acrosome (Fig. 4A) was ca. $2 \mu \mathrm{m}$ long and $1 \mu \mathrm{m}$ wide at the base. The acrosomal cavity contained diffuse periacrosomal material and a striated actin axial rod (Fig. 4B) which extended through the nuclear channel down to the partition (Fig. 4C) formed by adjoined nuclear membrane invaginations (nuclear channel, centriolar fossa) (Fig. 5G). The two centrioles were perpendicular to each other (Fig. 4A,C). The proximal centriole, with a pericentriolar element, located in the centriolar fossa (Fig. 4C). The distal centriole had a pericentriolar complex consisting of nine radially oriented elements (Fig. 4D). The distal centriole served as the basal body of the tail which had a typical arrangement of axonemal microtubules $(9+2)$. The centriolar apparatus was surrounded by a ring of five round mitochondria (0.6 $\mu \mathrm{m}$ in diameter) (Fig. 4A,E).

Two morphological types of sperm cell were found. The first type, which was more common, was characterized by a posteriorly directed tail (Fig. 4F). The second type was characterized by an anteriorly directed tail adjoining the sperm head (Fig. 4G). Apart from the orientation of sperm tail, the head morphology of these two types of sperm cell was similar. 


\section{Discussion}

Results of the present spermatogenesis study demonstrate that acrosomal development in Perna viridis begins with the production of proacrosomal vesicles in spermatogonia and spermatocytes. These findings are in agreement with reports on many bivalves studied (Longo and Dornfeld 1967; Reunov and Drozdov 1987; Eckelbarger et al. 1990; Reunov and Hodgson 1994). Similar observations have also been reported in other marine invertebrates with primitive spermatozoa and external fertilization such as the sipunculids (Klepal 1993; Reunov and Rice 1993), the priapulids (Reunov et al. 1992), the echinoderms (Atwood 1974; Bickell et al. 1980; Yamashita 1983), the nemertines (Reunov and Klepal 1997) and the brachiopods (Hodgson and Reunov 1994). In animals with modified sperm and internal fertilization, such as the oligochaetes (Ferraguti and Jamieson 1984; Hodgson and Jamieson 1992), the barnacles (Azevedo and Corral 1982), the gastropods (Amor and Durfort 1990), and the vertebrates (Johnson 1995; Pudney 1995), formation of acrosomal substance begins in spermatids. The reasons for the early arising of acrosomal material in the development of primitive sperms remain unclear. Yamashita (1983) and Yamashita and Iwata (1983) attempted to correlate this feature in echinoderms with the size of acrosome and the short duration of spermatogenesis. However, such a correlation was not found in the nemertines (Reunov and Klepal 1997). In our opinion, the formation of proacrosomal vesicles before spermiogenesis could be considered a feature typical of primitive spermatozoa.

Spermatocytes of $P$. viridis are flagellated, and formation of flagellum in pre-spermiogenic cells occurs widely in bivalves and other invertebrates (Atwood 1974; Eckelbarger 1984; Paulus 1989; Reunov et al. 1992; Hodgson and Reunov 1994). Early formation of the flagellum in spermatogonia and/or spermatocytes does not appear to be functionally significant. The formation of the flagellum is probably a rudimental or plesiomorphic feature inherited by germ cells from ancestral flagellated cells (Reunov and Hodgson 1994; Reunov and Klepal 1997).

The interesting findings in the spermiogenesis of $P$. viridis are the dual patterns of acrosome development as well as flagellum development among spermatids in a single individual. The two lines of acrosome development during spermiogenesis are summarized diagrammatically in Fig. 5. The first "typical" pattern (Fig. 5A-F) we defined for $P$. viridis is similar to that reported for other bivalves (Reunov and Drozdov 1987; Reunov and Hodgson 1994). A similar type of acrosome maturation has been observed during spermiogenesis of the priapulids (Reunov et al. 1992), the brachiopods (Hodgson and Reunov 1994), the echinoderms (Atwood 1974), the scorpions (Phillips 1976) and the insects (Wolf and Kyburg 1989). The second pattern (Fig. 5A'-F'), with the acrosomal vesicle differentiating at the basal region of spermatid prior to migration, has been reported in the sipunculids (Reunov and Rice 1993) and polychaetes (Eckelbarger 1984). Although both patterns of acrosome development have been reported in marine invertebrates, the coexistence of these two patterns has so far never been described in a single species. Nevertheless, only one morphological type of mature acrosome was formed in $P$. viridis from these two lines of acrosome development (Fig. 5G).

On the other hand, the two lines of tail development in $P$. viridis during spermiogenesis resulted in the formation of sperm cell with either a typical posteriorly directed tail or an anteriorly directed tail originating from the distal centriole, which has not been described in bivalves or any other mollusks. A similar bent-tail sperm cell, however, has been reported in the sea urchin Anthocidaris crassispina, and this was claimed to be a late spermatid as the bent tail would gradually straighten upon maturity (Au et al. 1998). A similar pattern of tail re-orientation may also be applied to $P$. viridis. Although retracted tail development has now been discovered in both urchin and mussel, the origin and significance of such development remain obscure.

The morphology of Perna viridis spermatozoa (Fig. 5G) is similar to other Mytilus spp. sperms which are morphologically conservative (Niijima and Dan 1965; Longo and Dornfeld 1967; Hodgson and Bernard 1986 a, b; Reunov and Drozdov 1987). Sperms with an elongated acrosome and an actin axial rod passing through the acrosomal cavity and the nuclear channel are typical of Mytilus spp. The striated appearance of the actin rod of P. viridis, similar to that of Mytilus edulis, is due to the presence of cross bridges between actin filaments (Tilney et al. 1987). These actin filaments do not pass through the nuclear membrane partitions. Similar partitions have also been observed in spermatozoa of Mytilus coruscus and M. edulis (Reunov and Drozdov 1987; Tilney et al. 1987), but not in M. edulis from other localities (Niijima and Dan 1965; Longo and Dornfeld 1967; Hodgson and Bernard 1986 a,b), M. galloprovincialis (Hodgson and Bernard 1986 a,b) and P. perna (Bernard and Hodgson 1985).

In conclusion, the unique features in the spermatogenesis of the green-lipped mussel $P$. viridis, are attributed to the presence of a dual pattern of acrosome development as well as flagellum development during spermiogenesis in a single individual. This kind of sperm development is the first reported for any species of the Mytilidae. Even though the sample size used in this study was not large, the second line of acrosome development and the retracted flagellum development occurred in all the male $P$. viridis individuals studied. It is not certain whether such dual patterns of development occurred naturally in $P$. viridis, or whether these were the results of animal exposure to toxic environmental agents. Future work will be carried out to sample more $P$. viridis individuals from different localities of known water quality in Hong Kong, along the South China Sea and other subtropical and tropical coastal areas in order to study the percentage occurrence of each developmental pattern at the individual and population levels, and to relate such occurrences to the water quality of the localities. 
Acknowledgements Dr D.W.T. Au and Prof. R.S.S. Wu are grateful to the Research Committee, City University of Hong Kong, for the award of Strategic Grant (no. 7000602) to study the ultrastructure of the green-lipped mussel. Dr A.A. Reunov was partly supported by The Russian Foundation of Fundamental Research (no. 96-04-49702). We are grateful to Miss Pamela Y.M. Wan and staff in the Electron Microscope Units of the University of Hong Kong and City University of Hong Kong for technical assistance.

\section{References}

Agard J, Kishore R, Bayne B (1992) Perna viridis (Linnaeus, 1758). First record of the Indo Pacific green mussel (Mollusca: Bivalvia) in the Caribbean. Caribb Mar Stud 3:59-60

Amor MJ, Durfort M (1990) Changes in nuclear structure during eupyrene spermatogenesis in Murex brandaris. Mol Reprod Dev 25:348-356

Atwood DG (1974) Fine structure of spermatogonia, spermatocytes and spermatids of the sea cucumber Cucumaria lubrica and Leptocynapta clarki (Echinodermata: Holothuroidea). Can J Zool 52:1389-1396

Au DWT, Reunov AA, Wu RSS (1998) Four lines of spermatid development and dimorphic spermatozoa in the sea urchin Anthocidaris crassipina (Echinodermata: Echinoidea). Zoomorphology 118:159-168

Azevedo C, Corral L (1982) Ultrastructural study of spermatozoon and spermiogenesis of Pollicipes cornucopia (Crustacea; Cirripedia) with special reference to nucleus maturation. J Submicrosc Cytol 14:641-654

Bernard RTF, Hodgson AN (1985) Fine structure of the sperm and spermatid differentiation in the brown mussel Perna perna. S Afri J Zool 20:5-9

Bickell L, Chia FS, Crawford BJ (1980) A fine structural study of the testicular wall and spermatogenesis in the crinoid, Florometra serratissima (Echinodermata). J Morphol 166:109-126

Cheung SG (1991) Energetics of transplanted populations of the green-lipped mussel Perna viridis Linnaeus (Bivalvia: Mytilacea) in Hong Kong. I. Growth, condition and reproduction. Asian Mar Biol 8:117-131

Cheung SG (1993a) Population dynamics and energy budgets of green-lipped mussel Perna viridis Linnaeus in a polluted harbour. J Exp Mar Biol Ecol 168:1-24

Cheung SG (1993b) The physiological ecology of Perna viridis (Bivalvia: Mytilidae) from contrasting environments in Hong Kong. In: Morton B (ed) The marine biology of the South China Sea, vol 15. Hong Kong University Press, Hong Kong, pp 114-123

Drozdov AL, Reunov AA (1986) The spermatogenesis and ultrastructure of spermatozoon of Modiolus. Tsitologia 28:1069-1074 (in Russian with English summary)

Eckelbarger KJ (1984) Ultrastructure of spermatogenesis in the reef-building polychaete Phragmatopoma lapidosa (Sabellariidae) with special reference to acrosome morphogenesis. J Ultrastruct Res 89:146-164

Eckelbarger KJ, Young GM, Cameron JJ (1989) Modified sperm ultrastructure in four species of soft-bodied echinoids (Echinodermata: Echinothuriidae) from the bathyal zone of the deep sea. Biol Bull 177:230-236

Eckelbarger KJ, Bieler R, Mikkelsen PM (1990) Ultrastructure of sperm development and mature sperm morphology in three species of commensal bivalves (Mollusca: Galeommatoidea). J Morphol 20:63-75

Ferraguti M, Jamieson BGM (1984) Spermiogenesis and spermatozoal ultrastructure in Hormogaster (Hormogastridae, Oligochaeta, Annelida). JSubmicrosc Cytol 16:307-316

Franzen A (1956) On spermiogenesis, morphology of the spermatozoon, and biology of fertilization among invertebrates. Zool Bidr Uppsala 3:355-482

Hodgson AN, Bernard RTF (1986a) Observations on the ultrastructure of the spermatozoon of two mytilids from the southwest coast of England. J Mar Biol Assoc UK 66:385-390

Hodgson AN, Bernard RTF 1986b. Ultrastructure of the sperm and spermatogenesis of three species of Mytilidae (Mollusca, Bivalvia). Gamete Res 15:123-135
Hodgson AN, Reunov AA (1994) Ultrastructure of the spermatozoon and spermatogenesis of the brachiopods Discinisca tenuis (Inarticulata) and Kraussina rubra (Articulata). Invert Reprod Dev 25:23-31

Hodgson AN, Jamieson BGM (1992) Spermatogenesis in the earthworm Microchaetus pentheri (Oligochaeta, Microchaetidae). Zoomorphology 112:57-66

Huang ZG, Lee CY, Mak PMS (1985) The distribution and population structure of Perna viridis (Bivalvia:Mytilacea) in Hong Kong waters. In: Morton B, Dudgeon D (eds) Proceedings of the Second International Workshop on the Malacofauna of Hong Kong and Southern China, Hong Kong 1993. Hong Kong University Press, Hong Kong, pp 465-471

Johnson L (1995) Efficiency of spermatogenesis. Microsc Res Technol 32:385-422

Klepal W (1993) Spermatogenesis and spermatozoa of Aspidosiphon muelleri (Sipuncula). An ultrastructural study. J Submicrosc Cytol Pathol 25:203-212

Lee SY (1986) Growth and reproduction of the green mussel Perna viridis L. (Bivalvia: Mytilacea) in contrasting environments in Hong Kong. Asian Marine Biol 3:111-127

Longo FJ, Dornfeld EJ (1967) The fine structure of spermatids differentiation in the mussel Mytilus edulis. J Ultrastruct Res $20: 462-480$

Niijima L, Dan J (1965) The acrosome reaction in Mytilus edulis. I Fine structure of the intact acrosome. J Cell Biol 25:243-248

Paulus W (1989) Ultrastructural investigation of spermatogenesis in Spongilla lacustris and Ephydatia fluviatilis (Porifera, Spongillidae). Zoomorphology 109:123-130

Phillips DM (1976) Nuclear shaping during spermiogenesis in the whip scorpion. J Ultrastruct Res 54:397-405

Pudney J (1995) Spermatogenesis in nonmammalian vertebrates. Microsc Res Techn 32:459-497

Reunov AA, Adrianov av, Malakhov VV (1992) Ultrastructural investigation of spermatogenesis of priapulid Priapulus caudatus. Tsitologia 34:76-82 (in Russian with English summary)

Reunov AA, Drozdov AL (1986) The ultrastructure of spermatozoa of bivalve molluscs Adula falcatoides and Septifer keenae. Biol Morja Vladiv 5:74-76 (in Russian with English summary)

Reunov AA, Drozdov AL (1987) Spermatogenesis and ultrastructure of spermatozoa of the mussel Mytilus coruscus. Tsitologia 29:260-266 (in Russian with English summary)

Reunov AA, Drozdov AL (1992) The acrosomal reaction of spermatozoa of four species of bivalve molluscs-mytilids. Tsitologia 34:89-93 (in Russian with English summary)

Reunov AA, Hodgson AN (1994) Ultrastructure of the spermatozoa of five species of south African bivalves (Mollusca), and an examination of early spermatogenesis. J Morphol 219:275-283

Reunov AA, Klepal W (1997) Ultrastructural investigation of spermatogenesis in nemertine worm Procephalothrix sp. (Palaeonemertini, Anopla). Helgol Meeresunters 51:125-135

Reunov AA, Rice ME (1993) Ultrastructural observation on spermatogenesis in Phascolion cryptum (Sipuncula). Trans Am Microsc Soc 112:195-207

Tilney LG, Fukui Y, DeRosier DJ (1987) Movement of the actin filament bundle in Mytilus sperm: a new mechanism is proposed. J Cell Biol 104:981-993

Wolf KW, Kyburg J (1989) The restructuring of the flagellar base and the flagellar necklace during spermatogenesis of Ephestia kuehniella Z. (Pyralidae, Lepidoptera). Cell Tissue Res 256:77-86

Yamashita M (1983) A fine structural study of spermatogenesis in the brittle-star Ophiura sarsii (Echinodermata: Ophiuroidea) with a demonstration of the precocious formation of the acrosome. J Fac Sci Hokkaido Univ 23:254-265

Yamashita M, Iwata F (1983) Ultrastructural observations on the spermatogenesis of the brittle star Amphipholis kochii (Echinodermata: Ophiuroidea). Publ Seto Mar Biol Lab 28:403-415

Communicated by H.-D. Franke 